racteristic vaginal discharge, a practitioner may well be excused for not having examined bis patient, although the inability of explaining this chronic exhaustion by diarrboa, or expectoration, or by profuse sweats, should lead him to suspect, that as this exhaustion originated in delivery, it might be kept up by something amiss in the womb. This long.continued exhaustion is sometimes caused by uncomplicated defective uterine involution, as in the following case.

Mrs. W- is a well-formed, healthy-looking lady, and is now twenty-six years of age. She had enjoyed good health, and married at twenty-three. She had a child nine months afterwards, then a severe attack of uterine inflammation, and before recovering from this, she became pregnant, about two months after delivery, for the second child was born eleven months after the first. She went on well and without a bad symptom till it was time to get up, and then she found she was too weak to stand, and during the following ten months her time was divided between bed and sofa. She was not hysterical in any sense of the word; she wished to be up and doing, but she could not walk or stand, and the debility persisted, although there was nothing tingibly wrong about her. She slept well, took a fair amount of food and wine, had judicious tonics, and did not lose flesh. She had not been able to nurse. I found a large flabby cervix, which admitted the first phalanx of the indicator; the body of the womb was regularly enlarged, painless to pressure, and moderately retroflexed. The wax bougie entered to the depth of over four inches. What I could see of the lining membrane of the cervix was very red. That was the only thing I found in addition to a very patulous os uteri, and defective involution. Possibly the entire lining memhrane of the womb was as red as the part I could see, but I rather considered this to be a congestive state caused by defective involution than the fag end of endometritis, of which there had been no symptoms. Twenty months of incessant labour, either physiological or morbid, was too much for the womb in this case. Its tissues were paralysed, and the defectively involuted womb reacted unfavourably on the spinal cord for about a year. In this case I freely used, twice a week, a strong solution of nitrate of silver inside and outside of the cervix, with the object of starting contraction by a local irritant. 'The patient was ordered alum and zinc injections, bromide of potassium at night, sulphate of quinine and extract of nux vomica in pills, and a stimulant embrocation to the abdomen. I followed this treatment for about a month without observing any amendment, till one day $I$ noticed that the os uteri was very properly and firmly contracted. I suppose that this was an indication that the whole body of the womb was waking up to healthier action, for the patient began to mend from that time, and gradually recovered the power of walking. When she left town the cervix had its right consistency, the body of the womb was smaller, and the wax bougie measured about an inch less than it did three months before. Four months after she left town Dr. Mcclintock found the womb in a healthy condition.

In many of these long-standing cases of defective uterine involution the result is not so fortunate, for the womb never returns to its right size unless by the better management of uterine involution after another confinement.

From what precedes it appears that defective involution, to become apparent, requires to be associated with some other pathological condition; that by itself it is seldom a disease, but much more frequently the enlargement of the area in which a disease may originate, be it congestion, inflammation, ulceration, a polypoid or other growth. Moreover, defective involution nut only magnifies the area of uterine disease-it makes it last longer and promotes relapses. The larger the womb, the greater its blood-supply, the more eccentric will be its blood-fluctuations, and the more difficult it will be to cure disease grafted on such a womb. Uterine involution being checked, there is a more or less extensive bag, with walls in a transitional state. The growth of the new muscular fibre may not proceed pari passu with the decay of the old; while the cervix has nearly recovered its right size and consistency, fatty degeneration may proceed too fast in the median region of the womb. This softness and pliability of the uterine walls clearly explain the frequent rise of post-partum uterine flexions; whereas in the nulliparous womb the cavity is linear, the walls singularly firm and thick-it is extremely rare to find them sof tened,-so there is no pliability of walls to account for flexions of the virgin womb. Dr. G. Hewitt has lately stated that in young women of a delicate constitution there is not unfrequently a considerable softening of the virgin womb, the result of the general want of tone; but until a statement so contrary to my own experience is confirmed by other observers and by the teaching of the dead-house, I shall be disposed to fear that Dr. G. Hewitt's finger has been unconsciously biased by the desire to find so satisfactory an explanation of uterine malformations of the virgin womb.

Diagnosis. - I have already said that a soft flabby mags extending from the pubes to the umbilicus is a form of defective involution to be only observed in the earlier part of puerperality; that, generally speaking, after the third week the enlarged womb is to be felt well gathered up above the pubes. A vaginal examination gives the impression of the womb being larger than it ought to be, and its size may be more accurately estimated by a rectal examination. $A$ still more correct measurement may be taken by means of a wax bougie, for, as in a womb of the right size, it should be brought up at a depth of two inches and a balf. If, after parturition, the bougie measures from three and a balf to five inches, the excess of length must be attributed to an enlargement of the body of the womb, unless it can be explained by unnatural elongation of the cervix. From what I see and learn, I believe the uterine sound is of ten used to the detriment of the patient, and $I$ will remind junior practitioners that during the two months of normal uterine involution, and for longer when it is defective, the walls of the womb are of a yellower colonr, of a more tragile texture, and are therefore more liable to be perforated. A wax bougie No. 4 takes the measure well, and can do no harm.

I have something to add about the treatment of defective aterine involution, but $I$ must reserve it for a concluding paper.

Sej mour-strect, Portman-square.

\section{A NOTE ON SENILE PNEUMONIA.}

\section{BY JAMES GREY GLOVER, M.D. EDIN., \&c.}

T'HERE has been a very satisfactory advance of knowledge of late years in regard to acnte pneumonia. This remark applies to our knowledge of its natural course, its seat, its tendency not to cause death, when primary, occurring in subjects previously healthy and not old, and when not treated antiphlogistically or in any other way extremely. This fact is the more important, as pneumonia represents the whole class of acute primary inflammations, of which it is one of the most common, as it used to be, if it is not still, the most fatal. The writings of Dr. John Hughes Bennett on pneumonia, based as they are on a very large and. accurate clinical experience, and showing a splendidly successful result of treatment, are of the greatest value, and they do great honour to English medicine. Since then Dr. Wilson Fox has well sustained the credit of our literature on this subject by his able exposition of it in his article - probably the best systematic account we have-in "Reynolds's System of Medicine."

I have nothing to add to these accounts of the subject in general. Like all other practitioners, I am struck with two features of the disease : first, its tendency to terminate in a crisis-especially a sweating crisis-days before the disappearance of the physical signs of consulidation; and secondly, its tendency to terminate favourably when not overtreated. My simple object in the present note is, by the record of three recent cases, to encourage a hope that the progress of time may justify the application of these two propositions to the case of pneumonia in old people. Old people have been rather excluded from the benefit of our more hopeful views of the disease. Dr. Wilson For quotes Prus to the effect that of 129 cases whose age exceeded sixty, 77, or 59 per cent., died. In a table of 2618 cases, by Huss, from which Dr. Fox quotes, there are only 4 cases between serenty and eighty, of which 2 , or 50 per cent., 
died. In Dr. Bennett's marvellous table of 125 cases of simple acute pneumonia without a death, there is but one case at sixty and but one at seventy. He gives no other cases above sixty but these. These figures seem to show that the disease is not very frequently seen at high agesat any rate in hospital practice.

I happen to have seen within the last few months, in private practice, three cases of pneumonia in female patients at the respective ages of seventy-five, seventy-nine, and sixty-seven. These have all recovered, though they were all very ill; and I confess that their recovery-perhaps partly due to their sex-surprised me and gave me new faith in the chances of recovery and in the use of a certain line of treatment in such cases. The cases were briefly as follows. I only give such details as indicate the nature of the case.

CASE 1.-Mrs. M-, aged seventy-five, had, on the 15th December, a prolonged and severe rigor. At $\mathrm{my}$ first visit there was little to be made out, in connexion with this, but a loud bruit nearly all over the chest. The next morning the temperature was $1002^{\circ}$; in the evening of this day $101 \cdot 2^{\circ}$, with an approach to bronchial breathing at the middle part of the right chest posteriorly. The next morning there was a temperature of $102^{\circ}$. This temperature was never exceeded. On the fifth day the bronchial breath. ing and dulness on percussion at the above part were marked. There was some wandering at nights. From the fourth day, for four or five days, the pulse was more or less intermitting. On the sixth day of the disease, in the morning, the temperature was $1002^{\circ}$, and the pulse 102 and intermitting. On the seventh day, the temperature was $99.8^{\circ}$, the pulse continuing quicker than it should be, and on the erening of this day $I$ had the pleasure of finding the tem. perature $98^{\circ}$, the pulse about 90 and less intermitting. The progress of reccvery was slow. There was a slight bedsore. The dulness and bronchial breathing continued at lenst ten days after the temperature fell. Nervous symptoms, particularly sleeplessness at night, which had been somewhat troublesome before this illness, persisted; but she gradually recovered her ordinary strength and bealth, and is now very well.

Th $\rightarrow$ treatment was simple. Confinement to bed of course. The continuous application of linseed poultices to the affected side; citrate of potash in solution, with a few minims of spirits of ammonia and nitric ether; beef-tea and milk, and after the first two or three days, two or three spoonfuls of brandy, or a corresponding amount of sherry every three hours.

CASE 2.-Mrs. M- in her seventy-ninth year, had a rigor on the 5th of March. Sent for me on the 6th. Found her with a temperature of $101^{\circ}$; severe cough; harsh respiration over the upper right apex posteriorly ; and the pulse, as is frequently, if not habitually, the case with her, intermitting. The tongue had the genuine pyrexial fur. The treatment was very much as in the previous case. On the 9th of March a little champagne was ordered. On the 16 th she was convalescent, though the pulse was intermitting. Though the breathing was never distinctly bronchial in character, it was distinetly harsh, and the attack had all the essential clinical characters of pneumonia of the apex, and was creditably surmounted at geventy-nine.

CASE 3.-I was asked to see Mrs. D-, aged sixty-seven, late on the night of May 29th, 1876. Found her feverish, and with rusty sputum, but could not get any distinct history of a rigor. The next morning, on the 30 th, the temperature was $102 \cdot 4^{\circ} \mathrm{F}$., there was decided bronchial breathing, increase of vocal resonance, and dulness at the middle of the right lung posteriorly. In the evening the temperature was $102.8^{\circ} \mathrm{F}$., the sputum viscid and rusty. On the morning of June 1st the bronchial whiff had given place to large crepitation. In the evening the temperature was $103^{\circ}$, and there was headache and much distress. I attributed this increased temperature and discomfort partly to the effect of four grains of carbonate of ammonia, which I had added to her mixture in the morning. I now discontinued this, and returned to a simple mixture of citrate of potash, nitric ether, and a few minims of ipecacuanha wine. For some days following she continued ill, with more or less fever, tongue thickly furred, and sometimes dry, a good deal of pain on the affected side, and some looseness of the bowels. On the evening of June 4th she felt very ill. Temperature $100 \cdot 8^{\circ}$; pulse 108 ; breathing tight, and coughing painful; tongue thickly furred and dry; bowels loose. To have a little ice to suck, and a mixture with aromatic confection and bismuth. On the morning of the 5 th temperature was $99^{\circ}$; the edges of the tongue were cleaning. She had found the ice a great luxury. In the evening the temperature was $99^{\circ}$. She "feared she was no better," but her dress was wet with perspiration, and the pulse slower, though intermitting. On the 6 th at $10 \mathrm{~A}$ M. the temperature was $976^{\circ}$. The pulse was very irregular, the heart beats being about twice as many as the pulsations of the radial. This want of correspondence between the heart and the pulse constituted a marked and somewhat anxious feature of the disease till the 9 th, when it is noted that the pulse was 72, without irregularity, and in perfect harmony with the cardiac pulsations. During this period brandy was given with water, at the rate of a dessertspoonful every three hours. The only troublesome symptom now was night cough, greatly relieved by a five-grain pill of ipecacuanha and squills. On June 13th the note is, "Râles over the right side posteriorly; feels weak, tongue clean." A little quinine was ordered, with a few minims of diluted sulphuric acid. On the 15 th the respiratory murmur was clear, and free from râles, and the patient felt stronger. From this time the recovery needs no comment. [Since writing the above my patient has had, but is now recovering from, an attack of subacute rheumatism, affecting the hands, wrists, and shoulders. She had so far recovered from her pneumonia as to leave her room, and has now no chest symptoms but a slight cough. Her pulse is regular, about 70 ; temperature $98^{\circ}$. She has never had rheumatism before; but a sister has suffered much from it. The feet are not affected. It will be noticed that between the attack of pneumonia and this rheumatic condition there was a clear interval of defervescence and convalescence of nearly a fortnight.]

Remarks. - I noed add little to the above record. My belief is, that during the pyrexial period the best treatment is a cooling and sustaining one-that of simple salines with beef-tea, milk, water; and, if there is great beat or feeling of heat, a little ice may be swallowed from time to time. Over the affected part I invariably order a large linseed poultice to be kept, and renewed every three or four hours. When the period of crisis comes, no time should be lost in giving such moderate doses of stimulant as seem to belp, and not to heat, the patient. The thermometer and the pulse together will guide the judicious practitioner in regard to the dose. I have seen nothing to indicate the good of such quantities of stimulants throughout the disease as Todd used to give; but facts of the kind above given, and the sensations of the patient, leave litcle room to doubt that a moderate allowance of alcohol at the time of crisis, or a little before, is to be regarded as a part of the "food convenient" for such cases. The prostration of the patient at this time, at whatever age, is generally very great, and, in elderly people especially, very apt to be fatal.

Highbury.

\section{ANEURISM OF THE ARCH OF THE AORTA, COINCIDENT WITH SEVERE SYPHILITIC SYMPTOMS.}

\section{BY FREDERICK ENSOR, M.R.C.S.}

TAKEN in conjunction with the recent discussions, as to the part played by the poison of syphilis in the production of those occult changes which, occurring in large arteries, result in aneurism, I think the following case worthy of report:-

F-, aged forty-five, a discharged soldier, was admitted into the Port Elizabeth Provincial Hospital on the 1st of June, 1875. He confessed to having had venereal disease, and drunk very freely; had large, unhealed, rupial sores on the forehead, back, arms, and legs; had a bad cough for four months, which had got worse lately; had a prominence on the chest, to the right of sternum; dulness on percussion over an area of about two inches obliquely across the sternum, with a visible pulsation; radials even; heart's 